community, good management, newish buildings, and comparatively generous funding. But it's becoming increasingly difficult to satisfy the expectations of patients and politicians. Neither Stranraer nor Dumfries can offer the access to the specialist services that can be expected in the centre of Glasgow, and the citizens and the local politicians have to accept that. There are huge compensations: the level of care for the more ordinary conditions that make up the vast majority of medical practice is probably better and certainly much more personal than in central Glasgow, and the place is so beautiful.
I look forward to returning in 10 years, assuming that the NHS still exists and that I'm still alive, sane, and employable-all doubtful assumptions.

Competing interests: I have a passion for all things Scottish including porridge, bagpipes, malt whisky, and my wife.

1 Dumfries and Galloway: where the NHS works well. $B M J$ 1980;281:438-40. 2 Smith R. To flourish or fade: the NHS in Dumfries and Galloway. BMJ 1989:299:727-30

Smith R. PFI: perfidious financial idiocy. BMJ 1999;319:2-3.

4 Scottish Executive Health Department. Fair shares for all: report of the National Review of Resource Allocation for the NHS in Scotland. Edinburgh: Scottish Executive Health Department, 1999. (The Arbuthnott report.)

\title{
The hospital of the future Better out than in? Alternatives to acute hospital care
}

\author{
Martin Hensher, Naomi Fulop, Joanna Coast, Emma Jefferys
}

Changing technology is probably the main force driving the substitution of healthcare resources. This is because new treatments, procedures, and diagnostic techniques allow conditions to be managed in different settings by different staff. Such change is generally incremental, but occasionally new technologies fundamentally change the organisation of care. For example, the development of effective chemotherapy in the 1940s allowed tuberculosis to be managed on an outpatient basis, which led directly to the closure of nearly 30000 hospital beds and the elimination of an entire class of hospital. Advances in primary prevention might also, in the long term, lead to a reduced need for admission to hospital. Yet such step changes are ultimately outside the hands of clinicians, managers, and policymakers, despite their intimate concern with the organisation, scale, and cost of the hospital sector. The policy debate has tended to focus on what might be described as the "appropriateness gap"-how to provide substitute care for inpatients who do not strictly need to be in hospital because of current technologies.

\section{Inappropriate location of care}

Most patients admitted to hospital in the United Kingdom have no alternative but to be admitted: they are severely ill and require interventions that are available only through the high technology facilities of acute hospitals. Similarly, most days of hospital care could not be spent in alternative settings because the patient requires facilities that are available only in acute hospitals. In studies looking at the use of acute hospitals, however, a sizeable minority of admissions and, particularly, days of stay, are classified as inappropriate. A tiny number of patients may require no care at all, and they could immediately return home. ${ }^{12}$ Most patients classed as inappropriate admissions, however, require care over and above that routinely provided, but which could be obtained from a lower technology alternative to the acute hospital.

Table 1 shows the extent to which hospital admission and care have been classified as inappropri-

\section{Summary points \\ Changes in diagnostic and treatment technologies, rather than policy interventions, are the most potent force leading to the substitution of one form of healthcare service for another}

Many inpatient bed days and admissions are deemed inappropriate- but the appropriateness of admission to hospital can tell us nothing about whether patients would be more cost effectively cared for outside hospital

Several services that attempt to be substitutes for hospital care-either by preventing admission or by hastening discharge-have been experimented with

Many apparent substitutes for hospital care seem, in the United Kingdom, to increase overall demand for services, with little impact on overall hospitalisation or costs

ate in recent studies. There are two methods of defining the extent of inappropriate care. The first is to use the judgments of various health professionals. More recent studies, however, have favoured the use of structured utilisation reviews, developed in the United States as a means of cost containment. ${ }^{3-7}$ Studies of the appropriateness of hospital use can show us the potential for employing alternative forms of care, although extensions to the basic tools are needed to identify what particular alternatives might be appropriate. ${ }^{12}$ Such studies cannot, however, show whether it would be better for either the patients or the health service if these alternatives were used in practice. Identification of acute hospitals as inappropriate cannot show that other forms of care are equally effective in terms of patient outcome or that other forms of care are less costly than care in an acute hospital. Only studies that
This is the

fourth in a series of seven articles

London School of

Hygiene and

Tropical Medicine,

London

WC1E 7HT

Martin Hensher

health economist,

London Health

Economics

Consortium

Emma Jefferys

health economist,

London Health

Economics

Consortium

Naomi Fulop

senior lecturer in

health services

management and

policy, Health Services

Research Unit

Department of

Social Medicine,

University of

Bristol, Bristol

BS8 2PR

Joanna Coast

lecturer in health

economics

Correspondence to:

M Hensher

henshm@hltrsa2.

pwv.gov.za

BMJ 1999;319:1127-30 
Table 1 Results from selected recent European studies of the inappropriateness of hospital utilisation

\begin{tabular}{|c|c|c|c|c|c|c|}
\hline First author & $\begin{array}{c}\text { Year of } \\
\text { publication }\end{array}$ & Country & Specialty or criteria & $\begin{array}{c}\text { Measure } \\
\text { used }^{*}\end{array}$ & $\begin{array}{l}\% \text { Inappropriate } \\
\text { admissions }\end{array}$ & $\begin{array}{l}\% \text { Inappropriate } \\
\text { days of stay }\end{array}$ \\
\hline Smith $^{3}$ & 1997 & $\begin{array}{c}\text { United } \\
\text { Kingdom }\end{array}$ & Emergency medicine & AEP & 6 & 45 \\
\hline Apolone $^{4}$ & 1997 & Italy & $\begin{array}{l}\text { Internal medicine, neurology, cardiology, } \\
\text { pulmonary disease, gynaecology, } \\
\text { general surgery }\end{array}$ & Modified AEP & 27 & 40 \\
\hline Coast $^{1}$ & 1996 & $\begin{array}{l}\text { United } \\
\text { Kingdom } \\
\text { (rural) }\end{array}$ & General medicine, care of elderly people & ISD-A & $\begin{array}{c}22(19.7 \% \text { of emergency } \\
\text { admissions }) \dagger\end{array}$ & 54 \\
\hline$\overline{\text { Coast }^{2}}$ & 1995 & $\begin{array}{l}\text { United } \\
\text { Kingdom } \\
\text { (urban) }\end{array}$ & General medicine, care of elderly people & ISD-A & $\begin{array}{c}24(19.1 \% \text { of emergency } \\
\text { admissions }) \dagger\end{array}$ & 61 \\
\hline Hayes $^{5}$ & 1995 & Ireland & $\begin{array}{l}\text { People aged } 65+\text { years, admitted } \\
\text { through accident and emergency or as } \\
\text { outpatients }\end{array}$ & AEP & $\mathrm{N} / \mathrm{A}$ & 29 \\
\hline$\overline{\text { Victor }^{6}}$ & 1994 & $\begin{array}{c}\text { United } \\
\text { Kingdom }\end{array}$ & All, excluding psychiatry, obstetrics & OBSI & $<1$ & $\mathrm{~N} / \mathrm{A}$ \\
\hline Victor $^{7}$ & 1994 & $\begin{array}{c}\text { United } \\
\text { Kingdom }\end{array}$ & All, excluding psychiatry, obstetrics & OBSI & $\mathrm{N} / \mathrm{A}$ & 14.6 \\
\hline
\end{tabular}

${ }^{*} \mathrm{AEP}=$ appropriateness evaluation protocol; ISD-A=intensity-severity-discharge with adult criteria; $0 B S \mathrm{~B}=0$ xford bed study instrument.

tProportions reduced further after review by general practitioners and consultant physicians of appropriate alternatives. See original studies ${ }^{12}$

compare directly the relative costs and benefits of alternatives to acute hospitals are able to indicate whether the patient (and the NHS) is better out than in.

\section{Preventing admission}

Many strategies aim at preventing the admission of patients to hospital and at providing more cost effective care for patients in alternative settings. Most also aim at improving the quality of service for patients and perhaps patient choice.

\section{Emergency admissions}

Strategies to prevent emergency admissions to hospital are perhaps the most widely discussed in the NHS. For those patients with pre-existing conditions-for example, asthma or diabetes-emergency admission to hospital can be prevented by better management of the disease to prevent acute events occurring and by better management of events once they occur. Prevention of emergencies is largely the responsibility of professionals working in primary care and in the community, and many strategies have emphasised better integration between these professionals, closer involvement of and commitment from patients themselves, and the adoption of evidence based protocols agreed by all local specialists, including staff in secondary care (shared care).

Better management of acute events has been achieved by developing and adopting clinical guidelines by important professionals, and by defining more clearly for patients and practitioners where and how to access the most appropriate emergency care. This is essential as preventing admission in these cases often relates to the speed with which patients can receive relevant care. Patients without pre-existing conditions who have an emergency requiring specialist assessment have several options. These include attendance at a general practitioner's surgery, primary care centre, minor injury unit, or accident and emergency department. Although these initiatives are not designed to prevent admission to hospital, they allow accident and emergency departments and medical staff at hospitals to concentrate on more serious problems. ${ }^{8}$
More likely to be important in avoiding inappropriate admission are medical assessment units. These allow general practitioners to refer emergencies directly to trained nursing staff where full backup services are available and test results can be provided within a short time. Integration with community or home care services may allow patients to be discharged from the unit without an inpatient admission.

\section{New technologies}

Most of these strategies are attempts to create more efficient systems based on better organisational and management structures. The introduction of new technologies has, however, often also been able to make care more effective and can have a big impact on reducing hospital stays for non-emergency cases-in some cases eliminating the need to stay at all. For example, equipment for home dialysis has enabled patients to control their condition at home when previously they would have had to be admitted to hospital.

Day surgery is perhaps the most frequently cited example of a novel technology eliminating the need to stay in hospital. Although day case surgery has been taken up enthusiastically it had not reduced overall admission rates or the total cost of treating patients. ${ }^{9}$ This is partly because it is difficult for any day surgery unit operating across all specialties in a district general hospital to achieve enough activity to eliminate the need for a ward in a single specialty - a necessary action if costs are to fall noticeably-and also because the day of surgery is the most costly part of any inpatient stay. The growth in day surgery seems to have led to a substantial increase in overall rates of surgery ${ }^{10}$ - some inpatient surgery has been substituted by day surgery, but this has been overshadowed by new surgical activity performed on an outpatient basis.

In the United Kingdom a similar situation applies to some of the innovations that may be alternatives to admission to hospital. They might truly prevent admission, or enable a large enough number of hospital beds to be eliminated to achieve overall savings. Innovations such as minor injury units, medical assessment units, 
and day case surgery are likely, if successful, to lead to an increase in overall demand on the service. Thus, their ability to substitute for existing services may be swamped by their impact on demand.

\section{Methods to facilitate early discharge from acute care}

Several methods to facilitate early discharge from acute hospitals have been developed in recent years. These include discharge planning, nurse led inpatient care, patient hotels, community or general practice hospitals, nursing homes, and hospital at home schemes.

Discharge planning and the use of nursing homes have often been overlooked in favour of schemes to facilitate early discharge. Nurse led inpatient care has developed as a means of providing rehabilitative nursing care to patients who no longer require medical care. ${ }^{11}$ Patient hotels have been advocated for patients whose discharge has been planned and who no longer require medical or nursing care. Little rigorous research has been conducted on any of these methods. ${ }^{11}$

Discharge to community hospitals is increasingly topical, but the limited evidence suggests that this option may add to overall admissions and bed use. ${ }^{12}$ Hospital at home schemes have proved the most popular method for attempting to facilitate early discharge. A national survey of health authorities indicated that most were either supporting or planning to support a hospital at home scheme. ${ }^{13}$ Hospital at home provides care in the patient's home which otherwise would have been provided in hospital. This means that the patient is discharged early from hospital-for example, after orthopaedic surgery-to his or her home and continues to receive care from hospital at home staff (nursing, treatment). Considerably more research evidence is available on this method of early discharge compared with the others, and this is summarised below.

\section{Evidence for hospital at home}

A systematic review of five randomised controlled trials of hospital at home found no differences in patient health outcomes ${ }^{14}$; three trials conducted since then indicate that outcomes (mortality, functional status, and quality of life) for patients in hospital at home did not differ from those for patients in hospitals receiving standard hospital care. ${ }^{15}{ }^{16}$ Outcomes at three months' follow up were similar. ${ }^{17}$ Hospital at home schemes have enabled patients to be discharged early from hospital. ${ }^{18}$ One study found total length of stay (both in hospital and then under hospital at home care) for hospital at home patients to be less than that for patients in hospital, ${ }^{19}$ whereas others have found total length of stay for patients in hospital at home to be greater. ${ }^{18}{ }^{20}$ Evidence on costs of hospital at home compared with standard hospital care is also mixed. One study found hospital at home more expensive per episode of care than standard hospital care. ${ }^{19}$ Another found no difference in total healthcare costs between hospital at home and hospital care for patients with hip or knee replacements or general medical patients, but costs were higher in hospital at home for women who had had a hysterectomy and patients with chronic
Table 2 Association between change in bed stock in private nursing homes and beds available in NHS hospitals, 1984 to 1996-7

\begin{tabular}{lcc} 
& Total NHS hospital beds & NHS acute hospital beds \\
\hline Pearson correlation coefficient $(r)$ & -0.998 & -0.9878 \\
\hline$P$ value (two-tailed) & $<0.0001$ & $<0.0001$ \\
\hline Linear regression results: & & \\
\hline $\mathrm{r}^{2}$ & 0.996 & 0.9757 \\
\hline Slope $(95 \% \mathrm{Cl})$ & $-0.8478(-0.8833$ to -0.8123$)$ & $-0.1958(-0.2163$ to -0.1753$)$ \\
\hline
\end{tabular}

obstructive airways disease..$^{20}$ Two others found that the costs to the NHS of hospital at home were lower than those for standard hospital care patients. ${ }^{15} 21$

\section{The closest substitute?}

For many years, the number of beds operated by private nursing homes in the United Kingdom has grown consistently. The figure shows the growth in nursing home beds and declining NHS hospital bed provision in England from 1984 to 1996/7.

As table 2 shows, the association between the declining overall bed stock in NHS hospitals and the growth in the number of nursing homes seems to be significant. During this time, for every five NHS hospital beds that closed, around six beds in private nursing homes opened. This is hardly surprising, given that the closure of many of the large institutions providing long term care for elderly people or for patients with mental illness or learning disabilities was achieved in part by moving patients into smaller care homes. There is also, however, a strong statistical association between reductions in the numbers of acute beds and growth in the number of beds in private nursing homes (with five beds in nursing homes opened for every acute bed closed).

Activity data on the private nursing home sector are not readily available, so it cannot be shown whether the workload in hospital can be directly substituted by the workload in a nursing home. However, the relation between bed numbers alone seems strong enough to suggest that nursing homes may be a very close substitute for hospital care.

\section{Substitutes or bridges?}

The following questions should be asked when considering services which purport to act as substitutes for hospital care:

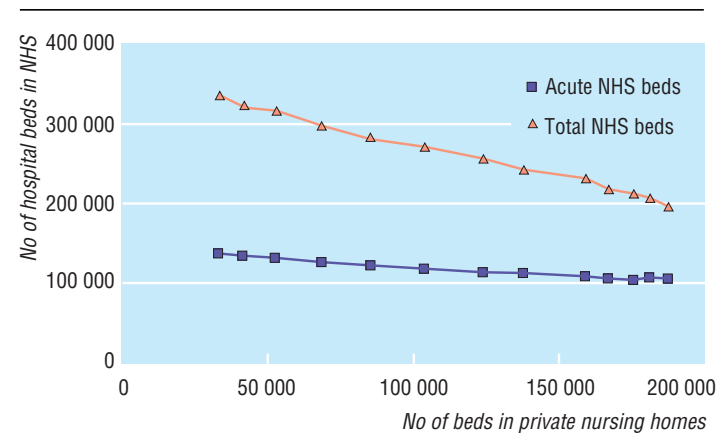

Fig 1 Relation between bed stock in the NHS and in private nursing homes between 1984 and 1996-7 (adapted from Department of Health, "Bed availability for England" and "Private hospitals, homes and clinics registered under Section 3 of the Nursing Homes Act 1975") 


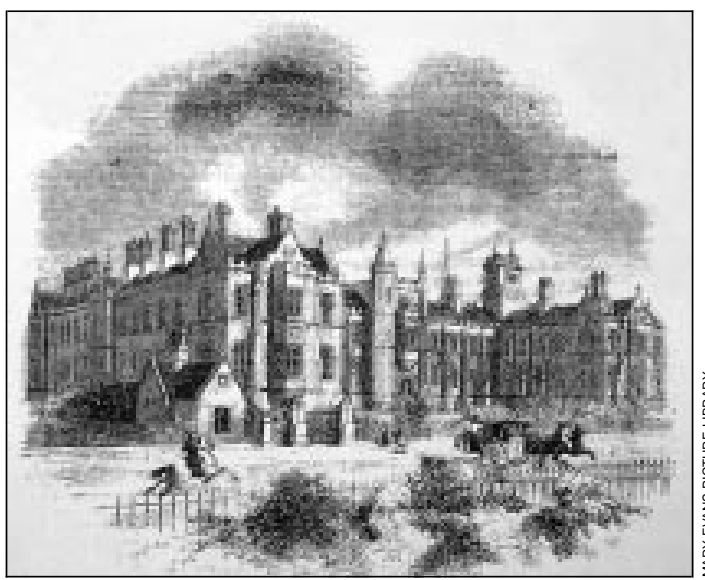

Fig 2 Brompton Consumption Hospital, London, 1862

- Are these strategies real substitutes or alternatives to hospital care, or are they complements (additions)?

- Do they allow better management of current demand, or do they increase activity?

- Is the result a more cost effective health service, a higher quality service, or both-or neither?

If we exclude the ability of nursing homes to be a direct substitute for long term patients or those needing continuing care, then the extent to which any of the alternatives to hospital described in this paper have truly acted as substitutes for hospital care is questionable. Staff, equipment, and drugs have substituted for beds in hospitals, allowing more patients to be treated more rapidly in a diminishing bed stock. As previous papers in this series have discussed, admission and hospitalisation rates in the United Kingdom show no sign of falling, while the number of finished consultant episodes rises. The alternative service models discussed here may have drawn off demand from hospital at the margins and may have shortened the tail of the length of stay distribution. Paradoxically, however, they may have emptied beds which then admitted yet more patients-at a faster rate than beds were being closed.

Other countries, especially the United States, have been able to reduce overall admission rates; perhaps because incentive structures and the relative prices of hospital substitutes have prevented the constant growth in inpatient activity seen in the United Kingdom. Evidence is lacking in the United Kingdom about whether many of the most frequently discussed alternatives to hospital are noticeably and consistently cheaper than hospital based care. It may ultimately be more profitable to consider alternatives to hospital not as substitutes that aim to reduce admission but as bridges between hospital and home, ${ }^{11}$ by means of which the quality of care can constantly be improved.

1 Coast J, Inglis A, Frankel S. Alternatives to hospital care: what are they and who should decide? BMJ 1996;312:162-6.

2 Coast J, Inglis A, Morgan K, Gray S, Kammerling M, Frankel S. The hospital admissions study: are there alternatives to emergency hospital admission? J Epidemiol Community Health 1995;49:194-9.

3 Smith HE, Pryce A, Carlisle L, Jones JM, Scarpello J, Pantin C. Appropriateness of acute medical admissions and length of stay. $J R$ Coll Physicians ateness of acute

4 Apolone G, Fellin G, Tampieri A, Bonanoni E, Crosti PF, Lanzi E, et al. Appropriateness of hospital use. Report from an Italian study. Eur J Public Health 1997;7:34-9.

5 Hayes CB, Johnson Z, Hynes M. Utilisation of hospital beds by the elderly - a cohort study of admissions to a teaching hospital. Ir Med J $1995 ; 88(4): 124-6$.
6 Victor CR, Khakoo AA. Is hospital the right place? A survey of "inappropriate" admissions to an inner London NHS trust. J Public Health Med 1994;16:286-90.

7 Victor C, Nazareth B, Hudson M, Fulop N. The inappropriate use of acute hospital beds in an inner London District Health Authority. Health Trends 1994;25(3):94-7.

8 Read S. Patients with minor injuries: a literature review of options for their treatment outside major AE्EE depts or occupational health settings. Sheffield: Sheffield Centre for Health and Related Research, University of Sheffield, 1994.

9 Abel-Smith B, Mossaiolos E. Cost containment and health care reform: a study of the European Union. Health Policy 1994;28:89-132.

10 Raftery J, Stevens A. Day case surgery trends in England: the influences of target setting and of general practitioner fundholding. J Health Serv Res Policy 1998;3:149-52.

11 Steiner A. Intermediate care: a conceptual framework and review of the literature. London: King's Fund, 1997.

12 Baker J, Goldacre M, Gray J. Community hospitals in Oxfordshire: their effect on the use of specialist inpatient services. I Epidemiol Community Health 1986;40:117-20.

13 Iliffe S. Hospital at home: buyer beware. J R Soc Med 1997;90:181-2.

14 Shepperd S, Iliffe S. Hospital at home compared to in-patient hospital care. In: Cochrane Collaboration. Cochrane Library. Issue 1. Oxford: Update Software, 1998.

15 Wilson A, Parker H, Wynn A, Jones J, Spiers N, Jagger C, et al. Hospital at home is as safe as hospital, cheaper, and patients like it more: early results from a randomised controlled trial. Society for Social Medicine abstracts. J Epidemiol Community Health 1997;51:593.

16 Richards S, Coast J, Gunnell D, Peters D, Pounsford J, Darlow M. Randomised controlled trial comparing effectiveness and acceptability of an early discharge, hospital at home scheme with acute hospital care. BMJ 1998;316:1796-801.

17 Shepperd S, Harwood D, Jenkinson C, Gray A, Vessey M, Morgan P. Randomised controlled trial comparing hospital at home care with inpatient hospital care. I: three month follow up of health outcomes. BMJ 1998;316:1786-91

18 Hensher M, Fulop N, Hood S, Ujah S. Does hospital at home make economic sense? Results of an economic evaluation of early discharge hospital at home care for orthopaedic patients in three areas of west London. JR Soc Med 1996;89:548-51.

19 Knowelden J, Westlake L, Wright K, Clarke S. Peterborough hospital at home: an evaluation. J Public Health Med 1991;13:182-8.

20 Shepperd S, Harwood D, Gray A, Vessey M, Morgan P. Randomised controlled trial comparing hospital at home care with inpatient hospital care. II: cost minimisation analysis. BMJ 1998:316:1791-6.

21 Coast J, Richards S, Peters T, Gunnell D, Darlow M, Pounsford J. Hospital at home or acute hospital care? A cost minimisation analysis. BMJ 1998;316:1802-6.

\section{Corrections and clarifications}

Population based study of social and productive activities as predictors of survival among elderly Americans

In this article by Thomas A Glass et al (21 August, pp 478-83), the currency conversions given for incomes were wrong. In the first paragraph of the section "Variables used in the analyses" the incomes should have been as follows: $<\$ 5000$ $(<£ 3125), \$ 5000-9999$ (£3125-6250); >\$10 000 $(>£ 6250)$.

Psychiatric disorder among children at time of entering local authority care: questionnaire study In this paper by $\mathrm{G}$ Dimigen et al (11 September, p 675), a wrong probability level was given for greater depression among children in residential care than among those in foster care. The level quoted (in the final paragraph of the methods and results section) was $\mathrm{P}<0.05$; it should have been $\mathrm{P}<0.06$.

Recent advances: neurology

In this paper by A J Larner and S F Farmer (7 August, pp 362-6) the first sentence in the section on multiple sclerosis should have read "Interferon betas (interferon beta-1b, Betaferon; interferon beta-1a, Avonex, Rebif) have been shown to reduce relapse rate in relapsing-remitting multiple sclerosis [not relapsing-remitting (non-progressive) multiple sclerosis] by about one third. ${ }^{14-16}$ " 